\title{
ADSORÇÃO DE CORANTES TÊXTEIS EM ZEÓLITA $\mathrm{NH}_{4} \mathrm{USY}$
}

\author{
Laíza Fernanda Curti Teixeira - laiza.curti@gmail.com \\ Universidade Federal do Espirito Santo - UFES
}

Fabricio Ventura Barsi - fabricio_barsi@yahoo.com.br

Universidade Estadual do Centro-Oeste do Paraná - UNICENTRO 


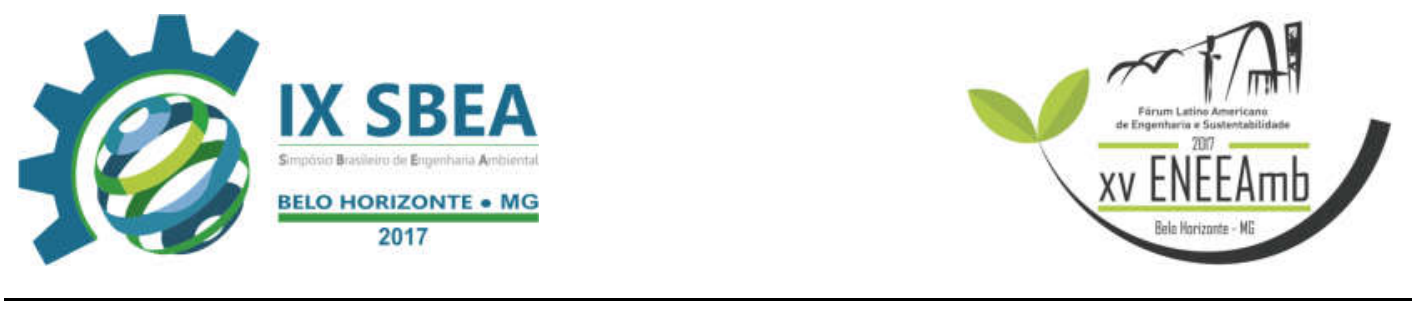

\section{RESUMO}

O presente trabalho tem como objetivo o uso da zeólita $\mathrm{NH}_{4}$ USY na remoção de corantes como efluente modelo de uma indústria têxtil. Todos os experimentos foram realizados em batelada, tanto para os estudos de tempo de equilíbrio de adsorção à temperatura ambiente como para as obtenções das isotermas de adsorção para os corantes à $25^{\circ} \mathrm{C}$ e $\mathrm{pH}=7$ em ambos os casos. Os dados obtidos no experimento foram ajustados pelos modelos de adsorção de Langmuir e Freundlich e seus parâmetros de equilíbrio foram avaliados. Observou-se que o corante Laranja Reativo 16 apresentou uma maior capacidade total de adsorção na zeólita estudada, cerca de 35\% superior à capacidade total de adsorção apresentada pelo corante Azul Qr-19, pois o mecanismo de adsorção do primeiro corante é melhor representado pelo modelo de Langmuir.

Palavras-chave: Adsorção, Corantes Têxteis, $\mathrm{NH}_{4} \mathrm{USY}$

\section{INTRODUÇÃO/OBJETIVO}

As indústrias geralmente produzem mais poluentes do que qualquer outro setor da sociedade, pelo o que se tem visto uma indústria, até mesmo que de pequena escala como uma indústria têxtil, possui uma carga poluidora equivalente à de um esgoto emitido por uma grande cidade (OGUNLAJA E AEMERE, 2009).

Esta tipologia industrial consome altos volumes de água, com uma demanda de 80 a 150 litros de água por quilo de tecido produzido, são estimados que $88 \%$ desse volume são descartados como efluentes e $12 \%$ consiste em perdas por evaporação. Além da quantidade de água, a aplicação de corantes, surfactantes e aditivos, que são utilizados em grande escala e são compostos orgânicos com grandes estruturas, contribuem para a complexidade do efluente têxtil (MINAS AMBIENTE, 2002; LEÃO et al., 2002).

Para a indústria têxtil a eficiência na remoção dos corantes de suas águas residuárias tem sido um grande problema, na etapa de tingimento podem ocorrer reações químicas indesejadas que prejudicam a eficácia desse processo acarretando assim em uma menor fixação do corante às fibras. Estima-se que aproximadamente $20 \%$ dos corantes têxteis são perdidos no processo de tinturaria das fibras e por consequência são descartados em efluentes (ZANONI et. al., 2001). 


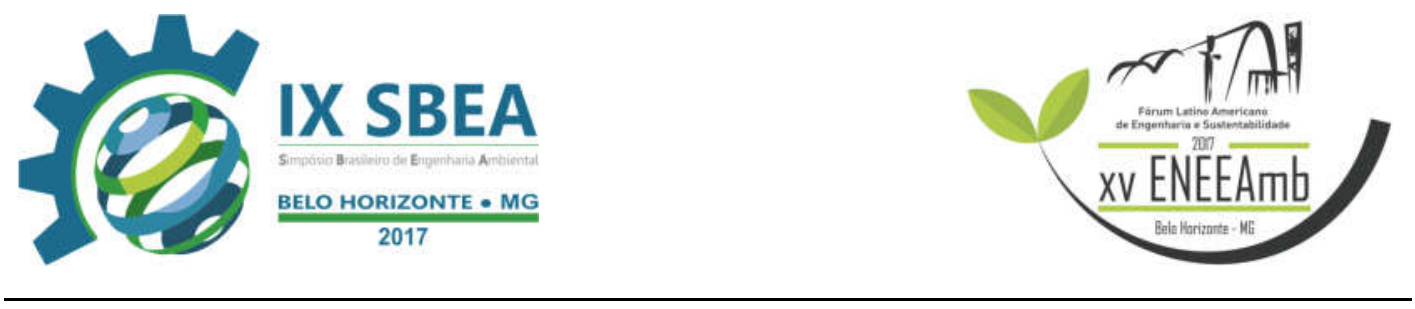

Quando não tratados adequadamente ao atingir mananciais tais corantes além de alterar a coloração natural dessas águas, afeta a atividade fotossintética da mesma ao diminuir a transparência da água e impedir a penetração de raios solares, causando prejuízos à biota aquática. (ZANONI et. al, 2001).

Os tratamentos de efluentes mais comumente usados no setor têxtil são direcionados para a remoção de cor e matéria orgânica, onde os compostos orgânicos são estabilizados por tratamento biológico, porém o mesmo é ineficiente na remoção de cor que deve ser realizada por um tratamento físico-químico (MINAS AMBIENTE, 2002).

Entre os vários tipos de tratamentos de efluentes, a adsorção tem sido considerada superior em termos de custo inicial, flexibilidade e simplicidade de projeto, facilidade de operação, etc. O primeiro passo para um processo de adsorção eficiente é a escolha de um adsorvente com alta seletividade, alta capacidade e longa vida (MAGDALENA et al., 2012).

Os principais modelos de adsorção são os de Langmuir e de Freundlich. O modelo de Langmuir considera o fenômeno de adsorção em superfície homogênea, considerando um número fixo de sítios de adsorção na superfície do adsorvente com formação de uma monocamada de adsorvato que não interagem com o meio ou entre si. As curvas das isotermas de Langmuir são obtidas de acordo com as Equações 1 e 2, nas formas normal e linearizada, respectivamente. Onde $\mathrm{Q}_{\mathrm{e}}$ é a quantidade adsorvida no equilíbrio; $\mathrm{C}_{\mathrm{e}}$ é a concentração em solução no equilíbrio; $K_{a d s}$ é a constante de adsorção e $Q_{\max }$ é a quantidade máxima de adsorvato que o material pode reter na sua superfície (ADAMSON e GAST, 1997; ORTIZ, 2000; CHAVES, 2009).

$$
\begin{gathered}
Q_{e}=\frac{Q_{\max } \cdot K_{a d s} \cdot C_{e}}{1+K_{a d s} \cdot C_{e}} \\
\frac{C_{e}}{Q_{e}}=\frac{1}{Q_{\max } K_{a d s}}+\frac{C_{e}}{Q_{\max }}
\end{gathered}
$$

O modelo de adsorção proposto por Freundlich considera que o processo de adsorção apresenta uma distribuição exponencial de calores de adsorção a partir da 


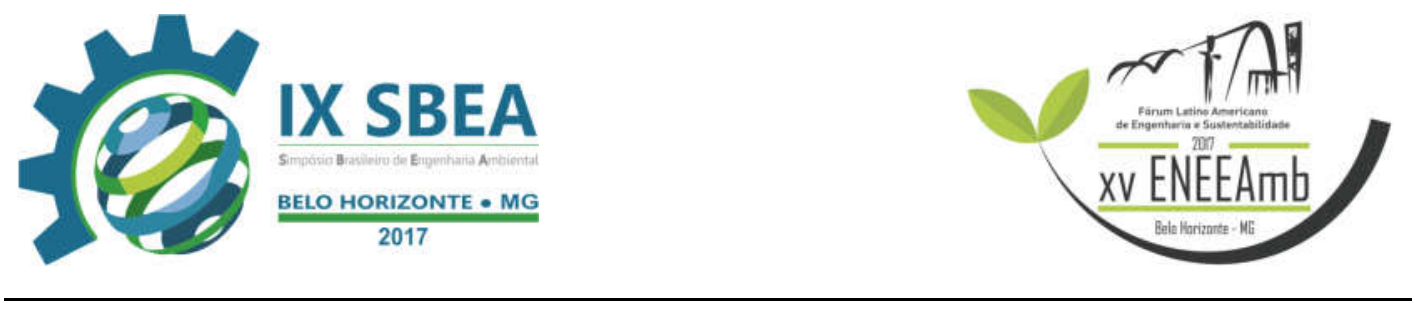

monocamada adsorvida proposta pela Equação 3 na forma não linearizada e pela Equação 4 na forma linearizada. Nessas equações, onde n representa uma constante de adsorção e os outros termos $\mathrm{Q}_{\mathrm{e}}, \mathrm{C}_{\mathrm{e}}$ e $\mathrm{K}_{\mathrm{ads}}$ apresentam os mesmos significados do modelo de Langmuir (ADAMSON e GAST, 1997; ORTIZ, 2000; CHAVES, 2009).

$$
\begin{gathered}
Q_{e}=K_{a d s} \cdot C_{e}^{1 / n} \\
\log Q_{e}=\log K_{a d s}+\frac{1}{n} \cdot \log C_{e}
\end{gathered}
$$

Um adsorvente que pode ser utilizado no tratamento de efluentes com alta concentração de corantes são as zeólitas, importantes adsorventes microporosos, que podem ser de origem natural ou sintética, e possuem características como seletividade e propriedades de troca iônica (ADEBAJO et. al., 2003).

As zeólitas são aluminossilicatos cristalinos constituídos pela combinação tridimensional de tetraedros $\mathrm{AlO}_{4} \mathrm{e} \mathrm{SiO}_{4}$ ligados entre si pelos átomos de oxigênio. Os átomos de alumínio e silício ocupam o centro do tetraedro enquanto os átomos de oxigênio ocupam os vértices. A combinação desses tetraedros que permite a formação de canais e cavidades na zeólita.

A zeólita Y é pertencente à família das faujasitas e possui um sistema de arranjo cristalino tridimensional cúbico (BRECK, 1974).

A união dos prismas hexagonais com quatro das faces hexagonais da sodalita forma um poliedro dentro do qual se encontra a supercavidade $\alpha$. A estrutura cristalina da família das faujasitas é mostrada na Figura 2. 

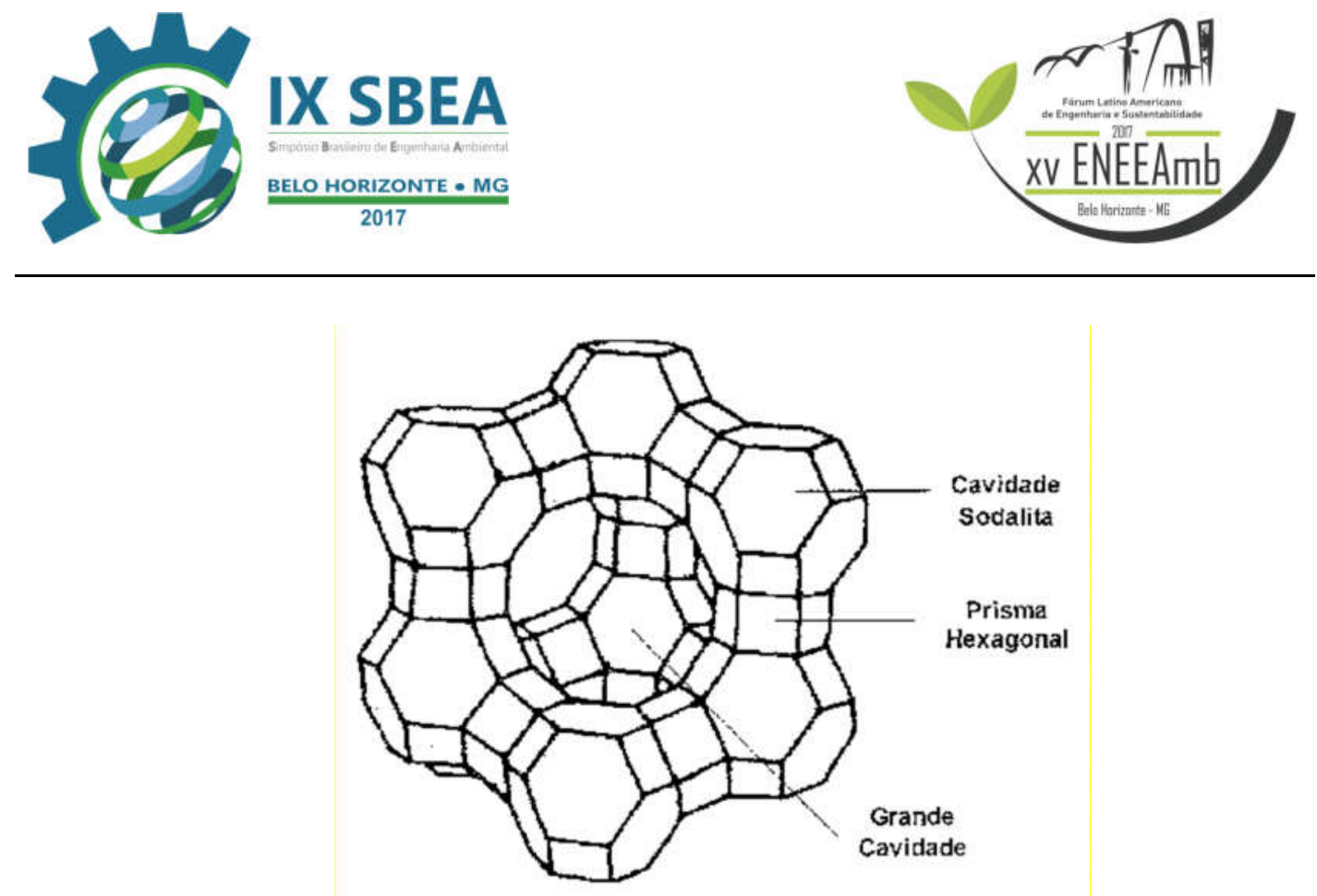

Figura 2. Estrutura cristalina da zeólita Y (SOBRINHO, 1993).

Essa estrutura cristalina com cavidades espaçosas permite uma alta eficiência das zeólitas no processo de adsorção (LUZ, 1995).

O objetivo desse trabalho foi estudar o processo de adsorção de corantes têxteis na zeólita $\mathrm{NH}_{4} \mathrm{USY}$ com concentração de corantes próximas à realidade da indústria têxtil.

\section{METODOLOGIA}

Foram preparadas soluções de corantes puros para serem utilizadas como efluente modelo com características semelhantes ao real em relação à concentração dos efluentes reais, para isso foram preparadas soluções dos corantes Azul Qr-19 e Laranja Reativo 16 em diferentes concentrações. Para a determinação das concentrações dos corantes adsorvidos, Azul Qr-19 e Laranja Reativo 16, foi utilizado o método espectrofotométrico em medidas de absorbância por UV-visível em comprimentos de onda de 592 nm e 494 $\mathrm{nm}$, respectivamente. As amostras foram centrifugadas para separação da zeólita antes da análise espectrofotométrica. 

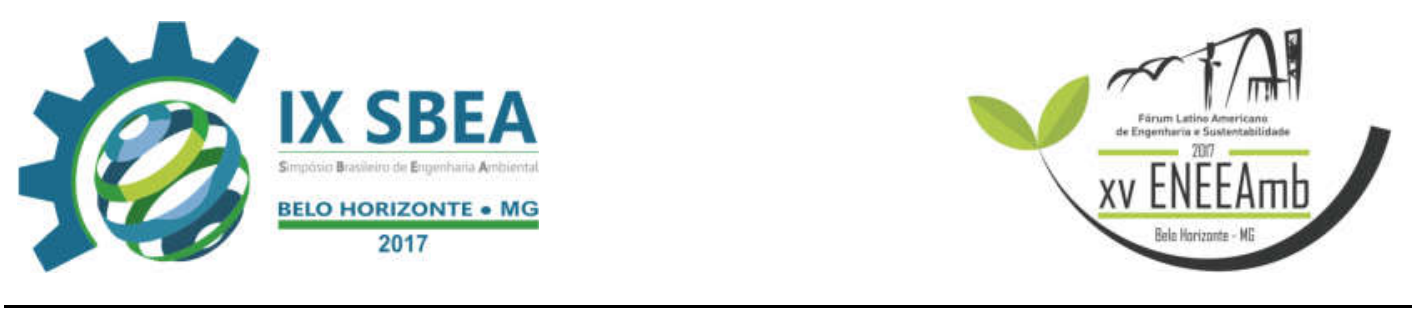

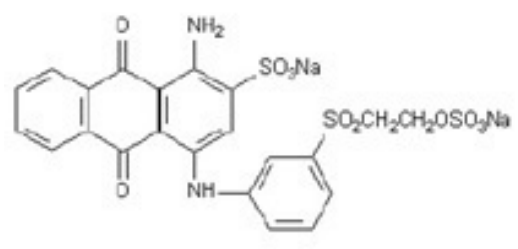

a

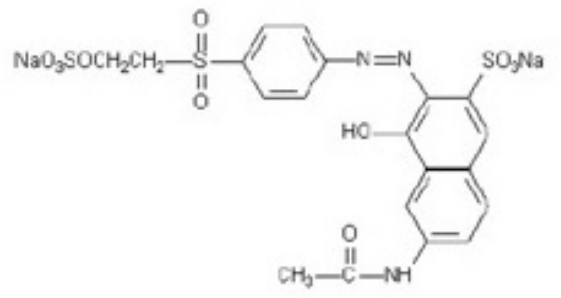

b

Figura 3. Estrutura química dos corantes reativos: Azul Qr-19 (a) e Laranja 16 (b).

Como material adsorvente foi empregada a zeólita comercial USY CBV712 adquirida junto à empresa Zeolyst International na sua forma amoniacal $\left(\mathrm{NH}_{4}{ }^{+} \mathrm{USY}\right)$, com razão molar $\mathrm{SiO}_{2} / \mathrm{AlO}_{3}$ igual a 12 e de área superficial igual a $730 \mathrm{~m}^{2} / \mathrm{g}$.

O ensaio para determinar o tempo de equilíbrio de adsorção para cada corante foi realizado em um processo em batelada com agitação constante e em temperatura ambiente. Para isso foi adicionado $1 \mathrm{~g}$ de zeólita em $400 \mathrm{~mL}$ da solução modelo de efluente na concentração de $50 \mathrm{mg} / \mathrm{L}$ sob agitação, retirando-se alíquotas de $30 \mathrm{~mL}$ em determinados tempos pré-estabelecidos: 0,5, 1, 2, 4, 6 e 24 horas.

Os ensaios para determinação da isoterma de adsorção para cada corante foram realizados com $1 \mathrm{~g}$ de zeólita em $500 \mathrm{~mL}$ da solução modelo em processo batelada com agitação constante, por 1 hora e em temperatura controlada de $25^{\circ} \mathrm{C}$, variando-se a concentração do efluente modelo em: 10, 35, 50, 100, 150, 200 e $250 \mathrm{mg} / \mathrm{L}$. O pH foi mantido em 7 durante os ensaios, já que, pela legislação vigente (BRASIL, 2011), o valor do $\mathrm{pH}$ final do efluente deve ficar em torno desse valor.

\section{RESULTADOS E DISCUSSÃO}

A quantidade de íons metálicos adsorvidos $\left(\mathrm{Q}_{\mathrm{e}}\right)$ foi calculada através do decréscimo da concentração de íons metálicos no meio, considerando o volume de adsorção e a quantidade de zeólita empregada:

$$
Q_{e}=\frac{\left(C_{0}-C_{e}\right) \cdot V}{m}
$$

onde $\mathrm{C}_{0}$ e $\mathrm{C}_{\mathrm{e}}$ são respectivamente as concentrações da fase aquosa antes e depois do período de tratamento com a zeólita $(\mathrm{mg} / \mathrm{L})$; V é o volume da fase aquosa (L) e m é a quantidade de zeólita empregada em (g). (PERGHER et al., 2005). 


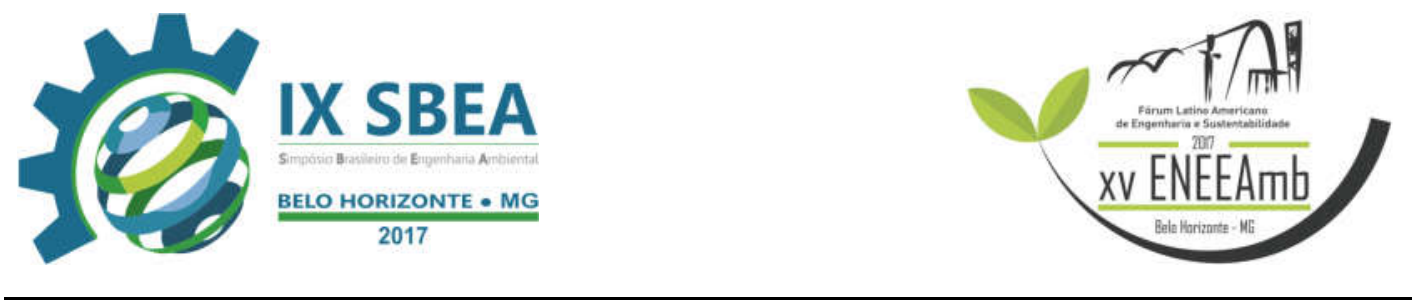

O resultado do estudo do tempo de equilíbrio de adsorção dos corantes Azul Qr19 e Laranja Reativo 16 sobre a zeólita $\mathrm{NH}_{4} \mathrm{USY}$ apresentado na Figura 4 revelou que o tempo mínimo necessário para obtenção do equilíbrio de adsorção foi de 1 hora para os dois corantes. Desta forma, o tempo de 1 hora foi utilizado em todos os ensaios de equilíbrio.

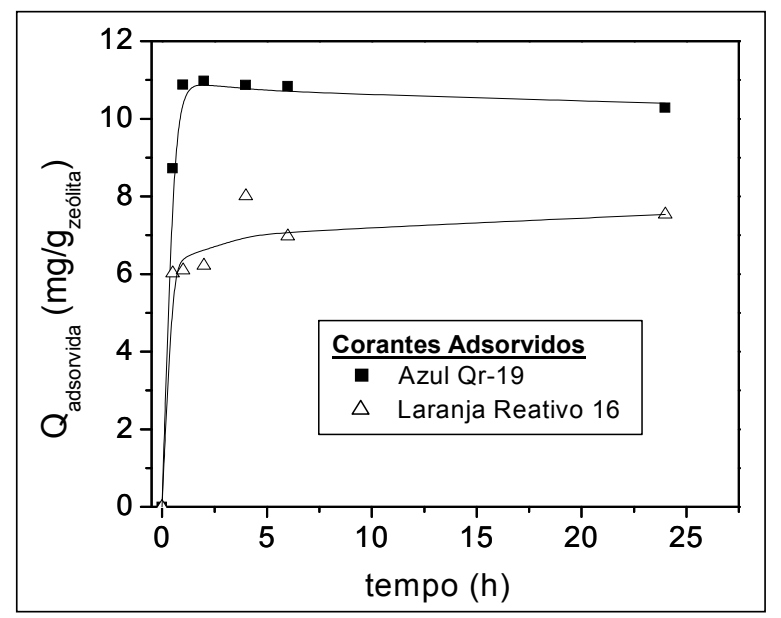

Figura 4. Cinética de adsorção dos corantes Azul Qr-19 e Laranja Reativo 16 sobre zeólita $\mathrm{NH}_{4} \mathrm{USY}$ em temperatura ambiente.

As isotermas de adsorção dos corantes Azul Qr-19 e Laranja Reativo 16 sobre a zeólita $\mathrm{NH}_{4} \mathrm{USY}$ foram determinadas através das quantidades adsorvidas em função da concentração de equilíbrio das espécies em solução. Na Figura 5 são apresentadas as isotermas de adsorção dos corantes realizadas à $25^{\circ} \mathrm{C}$ e $\mathrm{pH}$ igual a 7,0 .

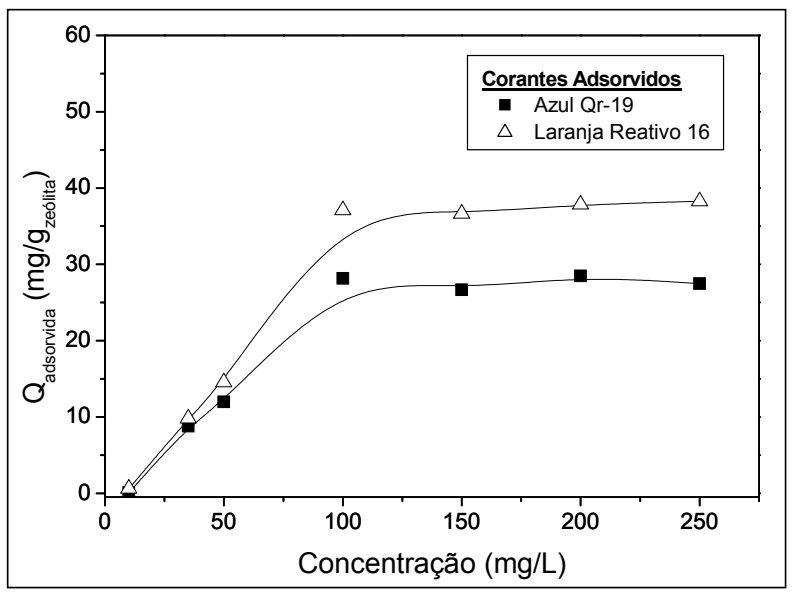

Figura 5. Isotermas de adsorção dos corantes Azul Qr-19 e Laranja Reativo 16 sobre zeólita $\mathrm{NH}_{4} \mathrm{USY}$ na temperatura de $25^{\circ} \mathrm{C}$ e $\mathrm{pH}=7$. 


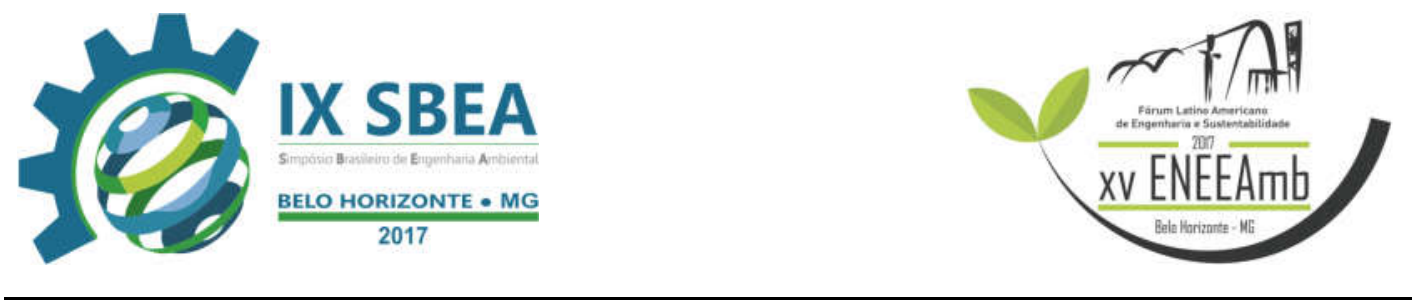

Pode-se observar que à $25^{\circ} \mathrm{C}$, o corante Laranja Reativo 16 adsorveu em maior quantidade (cerca de 35\% em maiores concentrações de corantes) quando comparado com o corante Azul Qr-19 utilizando as mesmas condições de adsorção na zeólita $\mathrm{NH}_{4}$ USY. Esse gráfico também indica que para os dois corantes utilizados a quantidade adsorvida sobre a zeólita alcança um patamar máximo da capacidade de adsorção diminuindo a percentagem de adsorção na zeólita mesmo aumentando a concentração do efluente, ou seja, a zeólita não consegue mais adsorver esses corantes indicando uma possível saturação da superfície e dos microporos da zeólita.

Para a interpretação dos dados experimentais obtidos foram utilizados dois modelos de adsorção, o modelo de Langmuir e o modelo de Freundlich, devido à facilidade de linearização dessas equações e consequente obtenção de seus parâmetros graficamente.

A Figura 6 apresenta as isotermas de adsorção de Langmuir (a) e Freundlich (b) para cada corante obtidas com o auxílio da Equação 2 e 4, respectivamente, a partir dos dados extraídos da Figura 5.
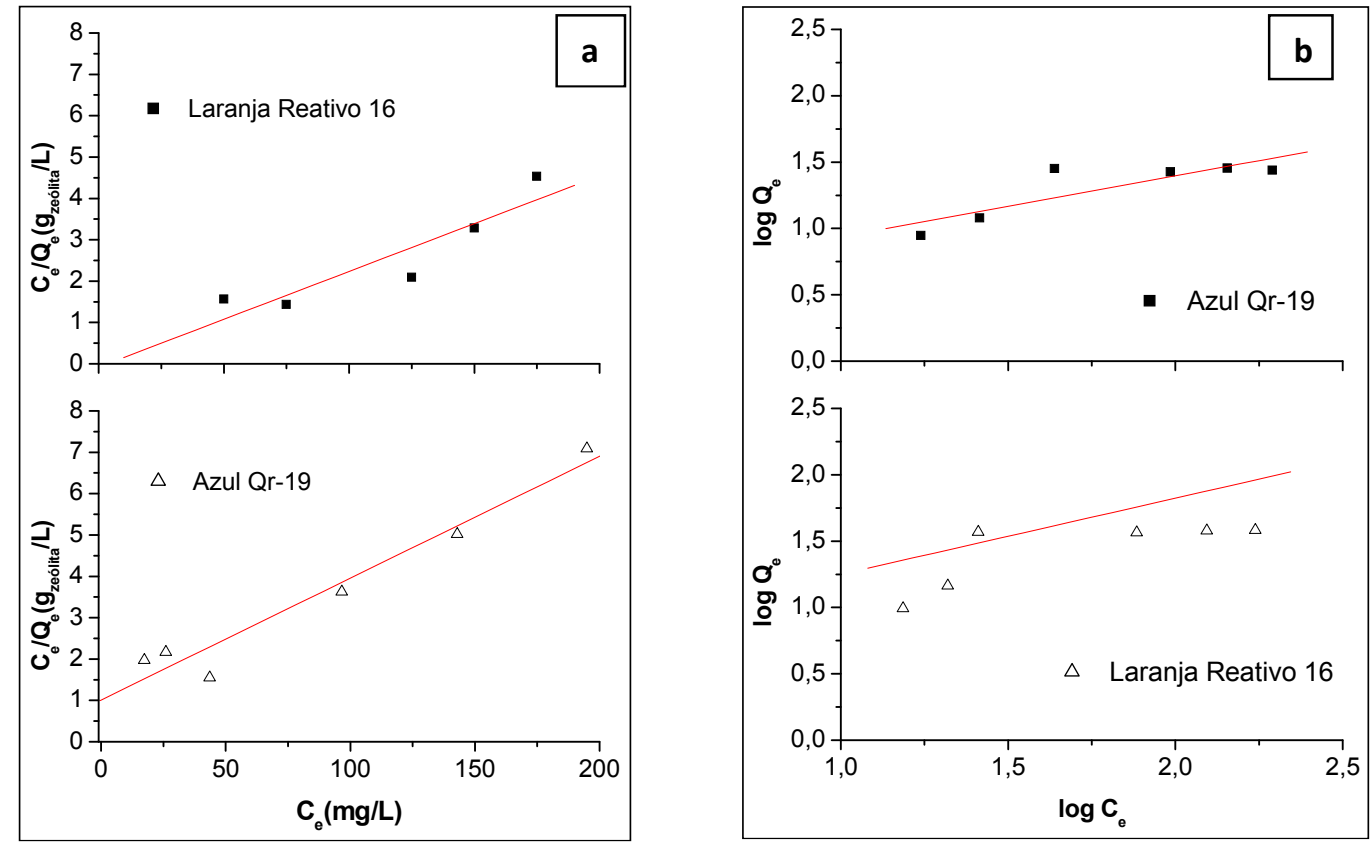

Figura 6. Isotermas de adsorção de Langmuir (a) e Freundlich (b) dos corantes Azul Qr-19 e Laranja Reativo 16 na temperatura de $25^{\circ} \mathrm{C}$. 


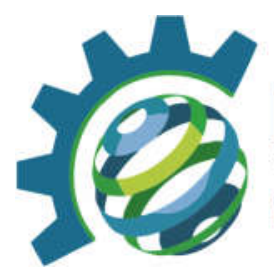

Os valores dos parâmetros obtidos pela equação de Langmuir ( $\mathrm{K}_{\mathrm{ads}}$ e $\left.\mathrm{Q}_{\max }\right)$ e pela equação de Freundlich ( $\mathrm{K}_{\mathrm{ads}}$ e $\left.\mathrm{n}\right)$ a partir dos dados experimentais para cada corante adsorvido são apresentados na Tabela 1 , com os respectivos valores de $\mathrm{R}^{2}$ para cada isoterma.

Tabela 1. Parâmetros das isotermas de Langmuir e Freundlich referentes às adsorções dos corantes Azul Qr-19 e Laranja Reativo 16 na zeólita $\mathrm{NH}_{4} \mathrm{USY}$ na temperatura de $25^{\circ} \mathrm{C}$

\begin{tabular}{|c|c|c|c|c|}
\hline Modelo & Corante & $\mathbf{K}_{\text {ads }}(\mathbf{L} / \mathbf{m g})$ & $\mathbf{Q}_{\max }\left(\mathbf{m g} / \mathbf{g}_{\text {zeolita }}\right)$ & $\mathbf{R}^{\mathbf{2}}$ \\
\hline \multirow{2}{*}{ Langmuir } & Azul Qr-19 & 0,029 & 33,944 & 0,9513 \\
\cline { 2 - 5 } & Laranja Reativo 16 & 1,728 & 21,670 & 0,8354 \\
\hline \multirow{2}{*}{ Freundlich } & & $\mathbf{K}_{\text {ads }}(\mathbf{L} / \mathbf{m g})$ & $\mathbf{n}$ & $\mathbf{R}^{\mathbf{2}}$ \\
\cline { 2 - 5 } & Azul Qr-19 & 3,020 & 2,183 & 0,7250 \\
\cline { 2 - 5 } & Laranja Reativo 16 & 4,742 & 1,743 & 0,9279 \\
\hline
\end{tabular}

Os dados experimentais obtidos para o corante Azul Qr-19 se adequam melhor ao modelo de Langmuir, já que o valor de $\mathrm{R}^{2}$ para o modelo linearizado foi igual a 0,9514 , contudo, em relação ao modelo de Freundlich, o valor obtido para $\mathrm{R}^{2}$ foi de 0,7250 . Para o corante Laranja Reativo 16 encontra-se uma melhor adequação dos dados experimentais ao modelo de Freundlich apresentando para o modelo linearizado um $\mathrm{R}^{2}$ de 0,9279 e para o modelo linearizado de Langmuir um $\mathrm{R}^{2}$ de 0,8354 . Esses resultados indicam que a maior adsorção apresentada pelo corante Laranja Reativo 16 frente ao Azul Qr-19 pode ser explicada pelo fato do corante Azul Qr-19 apresentar um mecanismo de adsorção próximo ao modelo proposto por Langmuir, que considera o fenômeno de adsorção ocorrendo em superfície homogênea, com número fixo de posições de adsorção disponíveis na superfície e com a formação de uma camada superficial monomolecular (CHAVES, 2009).

\section{CONCLUSÕES/RECOMENDAÇÕES}

$\mathrm{O}$ estudo do processo de adsorção de corantes na zeólita $\mathrm{NH}_{4} \mathrm{USY}$ consistiu na determinação da cinética de adsorção e na criação de isotermas de adsorção à $25^{\circ} \mathrm{C}$. Através da cinética de adsorção determinou-se que o tempo mínimo necessário para 

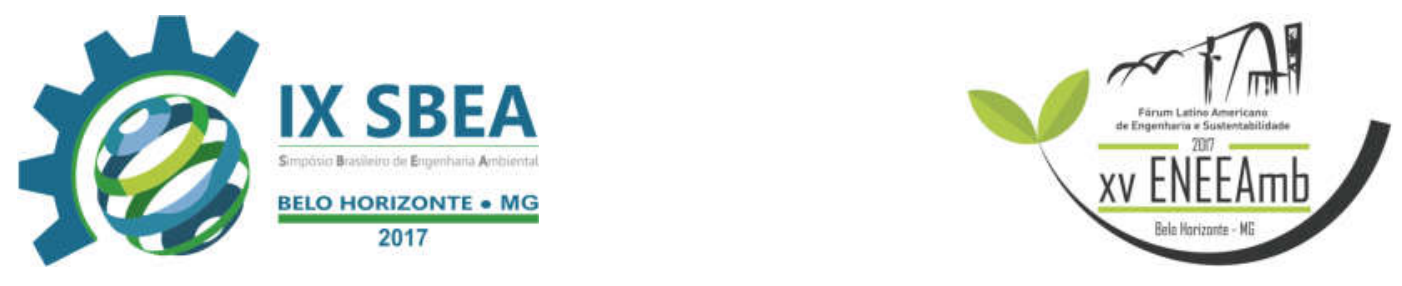

obtenção do equilíbrio de adsorção foi de 1 hora. No estudo das isotermas de adsorção para o corante Azul Qr-19 percebe-se uma adequação dos dados experimentais ao modelo de Langmuir, indicando possíveis interações de caráter químico entre a zeólita e o corante. Ao contrário do que ocorreu com o corante Laranja Reativo 16 cujo mecanismo de adsorção se adequa melhor ao modelo de Freundlich.

\section{REFERÊNCIAS BIBLIOGRÁFICAS}

ADAMSON, A.W. e GAST, A.P. Physical Chemistry of Surfaces, 1997, 784p. ADEBAJO, M. O. et al. Porous Materials for Oil Spill Cleanup: A Review of Synthesis and Absorbing Properties. Journal of Porous Materials, v. 10, n. 3, p. 159-170, 2003.

ALMEIDA, E.; ASSALIN, M.R.; ROSA, M.A.; DURÁN, N. Tratamento de efluentes industriais por processos oxidativos na presença de ozônio, Química Nova, v.27, n. 5, p. 818-824, set./out. 2004.

BRASIL. Conselho Nacional do Meio Ambiente. Resolução n ${ }^{\circ} 430$, de 13 de Maio de 2011.

BRECK, D. Zeolite Molecular Sieves, Structure, Chemistry and Use, 1974, 552p.

CHAVES, J.A.P. Adsorção de Corantes Têxteis sobre Quitosana. Tese de Doutorado, Universidade Federal da Paraíba, 2009.

LEÃO, M. D.; CARNEIRO, E. V.; SCHWABE, W. K.; RIBEIRO, E. D. L.; SOARES, A. F. S. Controle ambiental na indústria têxtil: acabamento de malhas. 2002, p. 356-380. LUZ, A. B., Zeólitas: propriedades e usos industriais. Rio de Janeiro: CETEM/CNPq, 35 p., Série Tecnologia Mineral n. 65, 1995.

MAGDALENA, C.P.; FUNGARO, D.A.; CUNICO, P. Adsorção de azo corante reativo utilizando material zeolítico: tempo de contato, $\mathrm{pH}$, temperatura e efeito de sais. Periódico Tchê Química, Porto Alegra, v.9, n.17, p. 48-59, jan. 2012.

MINAS AMBIENTE/CETEC. Controle Ambiental na Indústria Têxtil: Acabamento de malhas. Belo Horizonte, 2002.

OGULANJA, O. O.; AEMERE, O. Evaluating the efficiency of a textile wastewater treatment plant located in Oshodi, Lagos. African Journal of Pure and Applied Chemistry, v. 3, n. 9, p. 189-196, 2009.

ORTIZ, N. Estudo da utilização de magnetita como material adsorvedor dos metais $\mathrm{Cu}^{2+}$, $\mathrm{Pb}^{2+}, \mathrm{Ni}^{2+}$ e $\mathrm{Cd}^{2+}$, em solução. São Paulo, Instituto de Pesquisas Energéticas e Nucleares - IPEN, 2000. (Tese).

PERGHER, S. B. C.; Caovilla, M.; Detoni, C.; Machado, N.R.C.F. Remoção de $\mathrm{Cu}^{+2}$ de soluções aquosas em zeólita Nax. Efeito da granulometria. Química Nova. 2005, 28.

SOBRINHO, E.V. Preparação e Caracterização da Zeólita Y com Alto Teor de Silício Obtida por Desaluminização em Série. 1993. 146 f. (Tese)

ZANONI, M. V. B.; CARNEIRO, P. A. O descarte dos corantes têxteis. Ciência Hoje, v. 29, n. 174, p. 61-64, out. 2001. 